\title{
Efficiency of Acceptance and Commitment Therapy on Psychological Well- being and Sexual Function in Women with Infertility History
}

\author{
Monireh Hasanzadeh $^{1}$, Bahman Akbari ${ }^{* 2}$ Abass Abolghasemi ${ }^{3}$
}

1. PhD Student, Department of Psychology, Azad University of Rasht, Rasht, Iran

2. Associate Professor, Department of Psychology, Azad University of Rasht, Rasht, Iran

3. Professor, Department of Psychology, Guilan University, Guilan, Iran

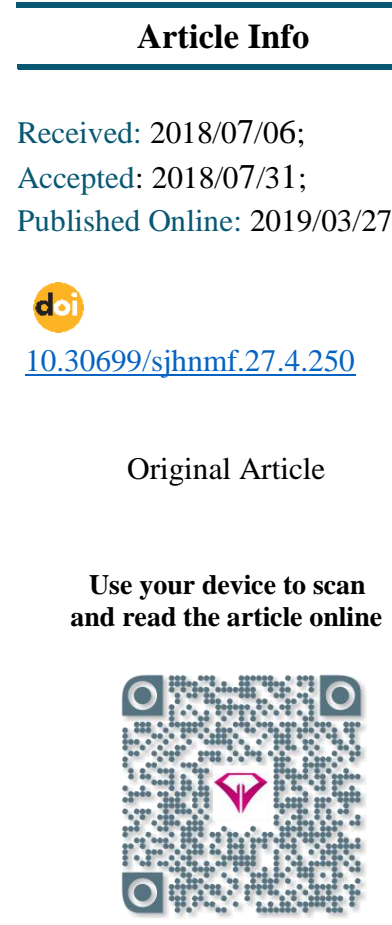

\section{ABSTRACT}

Introduction: Women with infertility have psychological and sexual problems; therefore, the aim of this study was to determine the effectiveness of acceptance and commitment therapy (ACT) on psychological well-being and sexual function of women with a history of infertility.

Methods: This was a semi-experimental pretest-posttest study with control group. A total of 30 infertile women referred to the Mehr Infertility Clinic in Rasht city during the 6 months (October 2017 to March 2018) were selected by available sampling method and randomly assigned to two groups of acceptance and commitment therapy $(\mathrm{n}=15)$ and control group $(\mathrm{n}=15)$. They completed the psychological well-being Reef and the sexual function of women Rosen questionnaire before and after the intervention and after 2 months follow-up. Data were analyzed by SPSS 19 and using multivariate covariance analysis and repeated measure ANOVA.

Results: Mancova showed that the ACT therapy in post-test stage had a significant effect on psychological well-being $(P<0.01)$ and its components included self-acceptance, positive relationships with others $(P<0.01)$, autonomy and life Purposeful life $(P<0.05)$ and sexual function $(P<0.01)$ and that the effect of ACT was Remained to follow up stage.

Conclusion: According to the results, it can be said that ACT therapy has an effective role in promoting the psychological well-being and sexual function of women with a history of infertility.

Keywords: Acceptance and Commitment Therapy, Psychological well-being, Sexual function, Infertility

Corresponding Information:

Bahman Akbari, Associate Professor, Department of Psychology, Azad University of Rasht, Rasht, Iran. Email: bakbari44@yahoo.com

Copyright ( $)$ 2019, This is an original open-access article distributed under the terms of the Creative Commons Attribution-noncommercial 4.0 International License which permits copy and redistribution of the material just in noncommercial usages with proper citation.

\section{How to Cite This Article:}

Hasanzadeh M, Akbari B, Abolghasemi A. Efficiency of Acceptance and Commitment Therapy on Psychological Well-being and Sexual Function in Women with Infertility History. Avicenna J Nurs Midwifery care. 2019; 27 (4):250-259 
اثربخشى درمان مبتنى بر يذيرش و تعهد بر بهزيستى روانشناختى و عملكرد جنسى زنان با سابقة نابارورى

منيره حسنزاده'، بهمن اكبرى ץ"*، عباس ابوالقاسمى

ا. . كارشناس مامايى و دانشجوى دكترى روانشناسى عمومى، كروه روانشناسى، دانشكاه آزاد /سلامى واحد رشت، كيلان، ايران

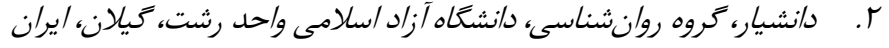

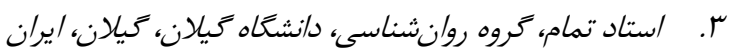

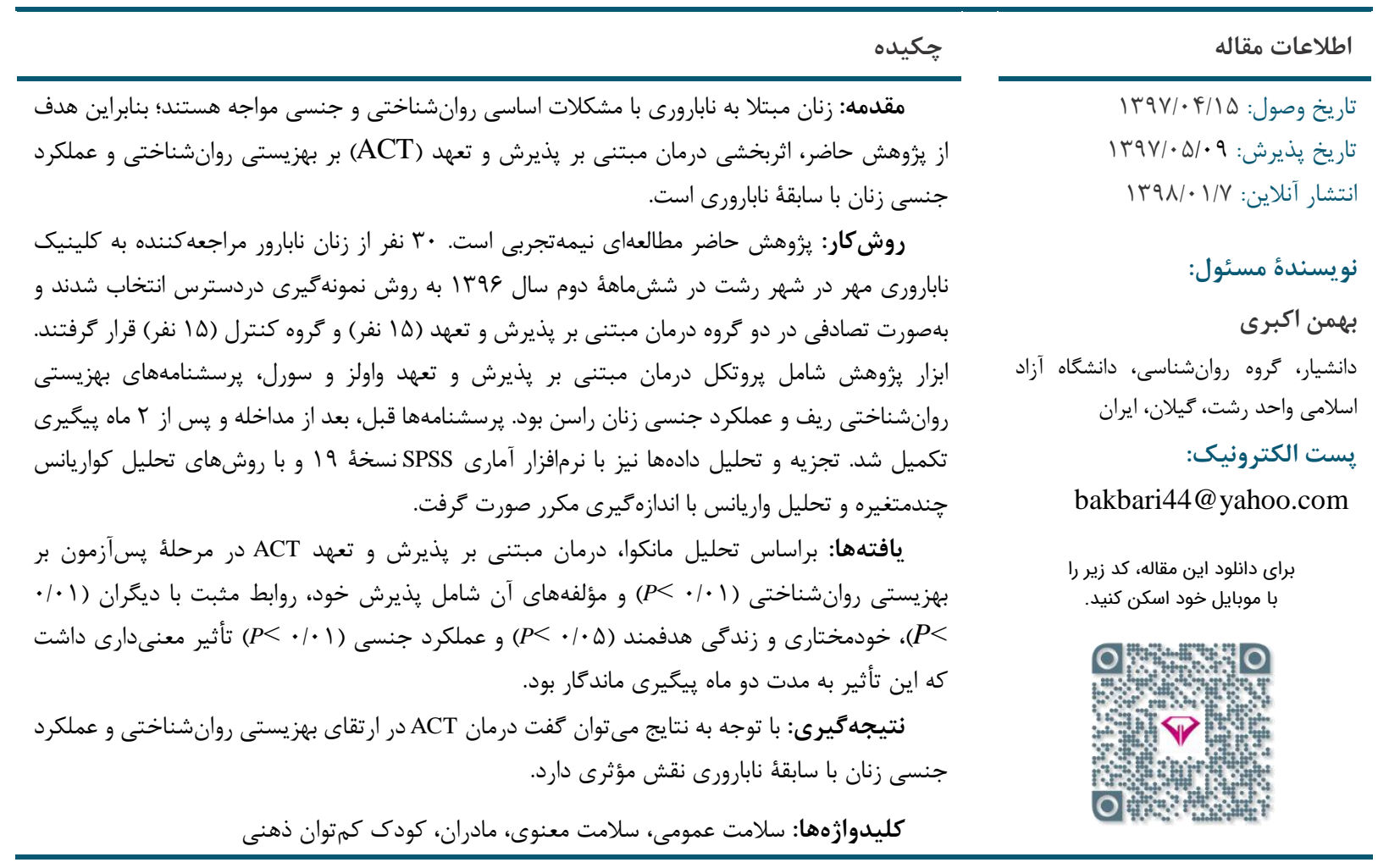

مقدمه

مواجه مىشود، افراد با ابهام دوسويهاى روبهرو مىشوند. از ديدكاه روانشناختى تمايل براى فرزنددارشدن وجود دارد، اما جنين مورين فرايندى در بعد جسمانى ممكن نيست و اين ابهام استرس زيادى

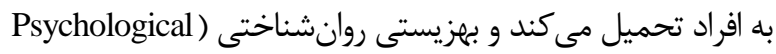

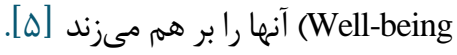

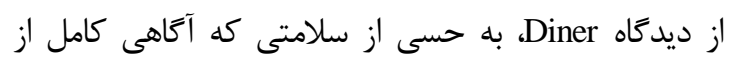
تماميت و يكيار جكَى در تمام جنبههاى فردى را شامل مىشود، بهزيستى روانشناختى مى گويند. بهزيستى روانى نيز از سه مؤلفهُ

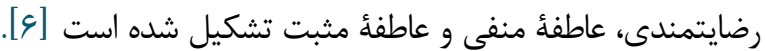
از سوى ديخر مطالعات دربارٔ بيمارانى كه در كلينيكهاى نابارورى حضور مىيابند، نتايج بيجِيدهاى از نظر بهزيستى روانشناختى به

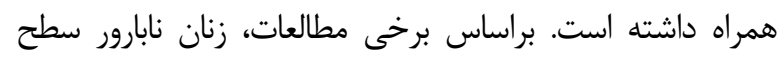

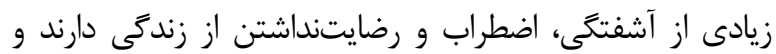

يكى از مشكلات شايع در زنان كه سلامت روانى و جنسى آنان را بر هم مىزند، نابارورى (Infertility) است. تعريف نابارورى براساس منابع و كتب يزشكى اين گونه است: زوجينى كه يس از يك سال ازدواج و زندگى مشترك، بدون استفاده از روشهاى

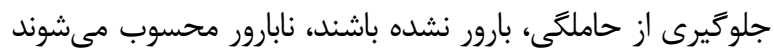

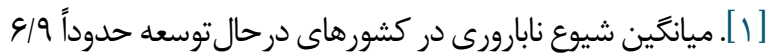
درصد تا س/9 درصد برآورد شده است [ب]. در سالهاى اخير، ميانگين كلى نابارورى در ايران ب/rا درصد كزارش شده است.

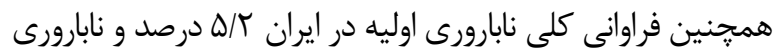

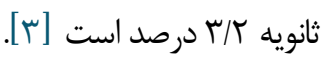
نابارورى بيمارى نيست، اما از آنجا كه بر تمام جنبههاى زندگى

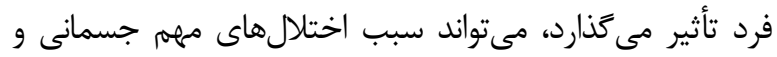

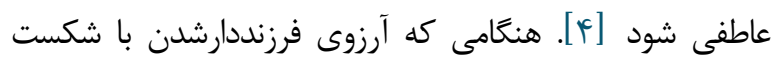


با علاقهُ روبهرشدى مواجه شده است و يكى از درمانهاى رفتارى

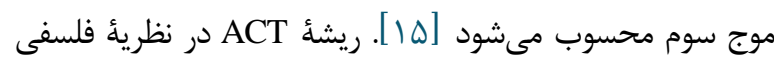
زمينه گرايى عملكردى نهفته است و بر برنامهاى تحقيقاتى درمورد

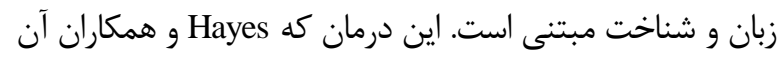

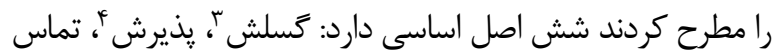

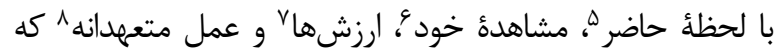

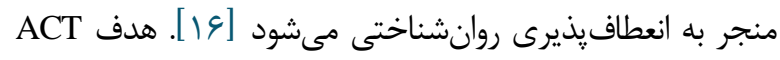
اين است فرد بهجاى اجتناب از افكار، احساسات، خاطرهنها و و

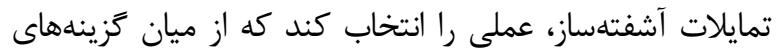

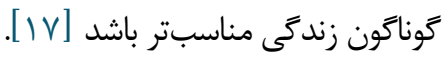
اثربخشى ACT بر انواع اختلالات روانى از جمله اختلالات

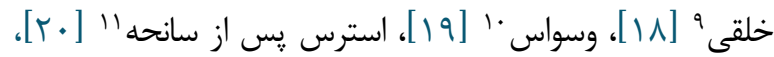

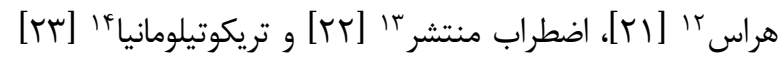

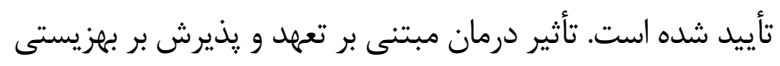

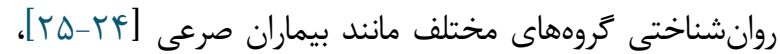

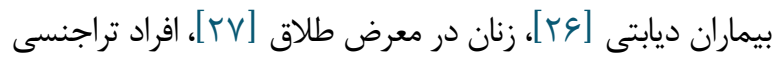

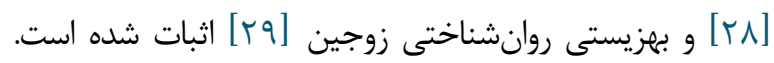

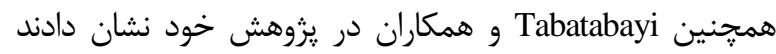

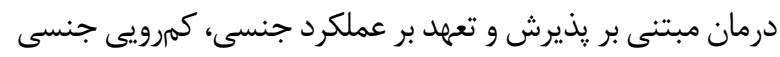

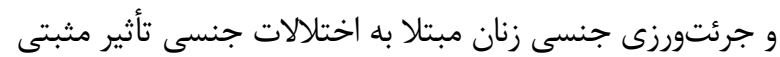

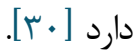

نابارورى از مشكلاتى است كه بهتدريج و در صورت عدم درمان

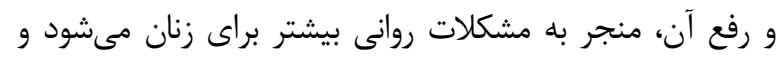

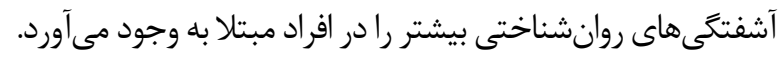
امروزه پِيشرفتهاى نوين علم يزشكى توانسته است در بسيارى از

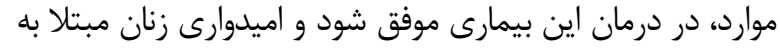

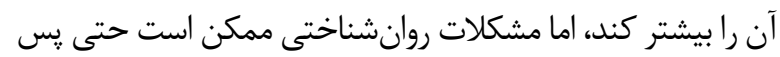
از درمان نابارورى نيز كم يا زياد يابر جا بماند كه اين فرايند با توجنه

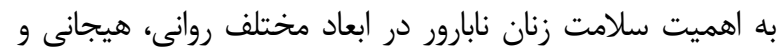

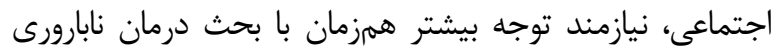

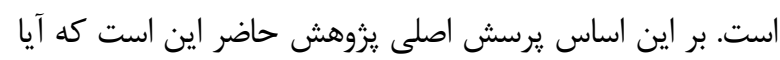

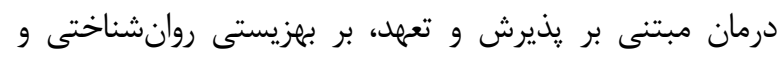

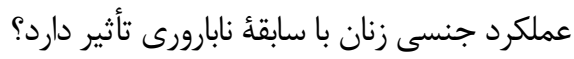

\footnotetext{
8. Committed Action

9. Mood Disorders

10 . Obsession

11. Posttraumatic Stress Disorders

12. Panic

13. General Anxiety

14 . Trichotillomania
}

احساس امنيت نمى كنند. درنتيجه بهزيستى روانشناختى آنها از

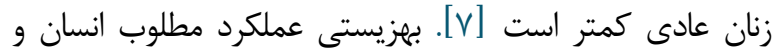

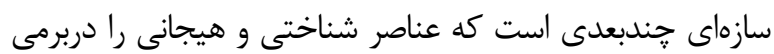

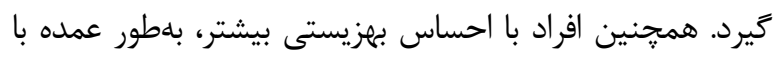

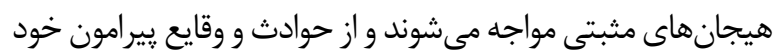
ارزيابى مثبتى دارند؛ درحالى كه كروه مقابل بيشتر هيجانهان إناى

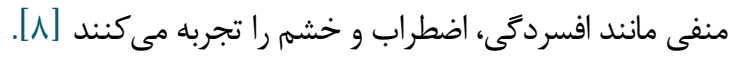
علاوه بر اين، نابارورى ممكن است بر سطح روابط زناشويى إنى

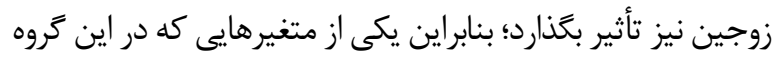

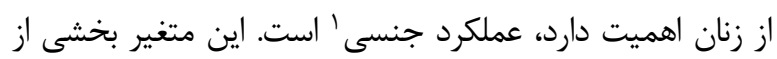

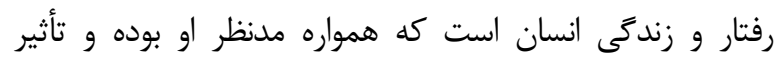
جشمخيرى بر كيفيت زندگى فرد و شريك جنسى او داشته است. بدينمنظور كاركردهاى جنسى اختلالى در روانيزشكى محسوب ردئ

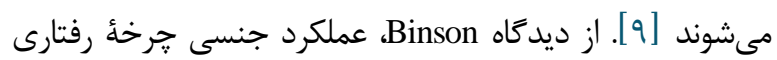

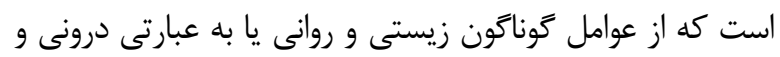

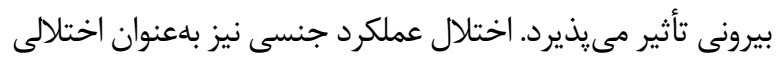
در جرخأ پاسخ جنسى يا درد هنغام رابطؤ جنسى تعريف شده [است [1]]

م و و همكاران، با بررسى نارضايتى جنسى و

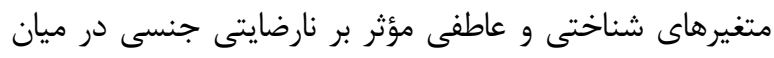

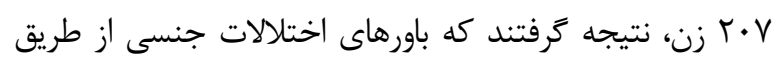
عوامل مستعدكننده (شامل استنباط افكار و عواطف منفى إنى خودبهخودى) بر عملكرد جنسى تأثير كذارند. اين امر فرايند تحريك أنسار

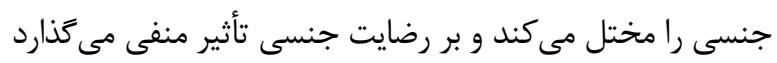

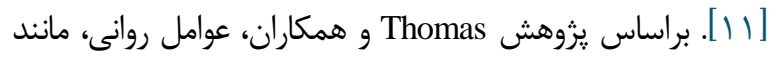

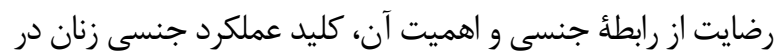

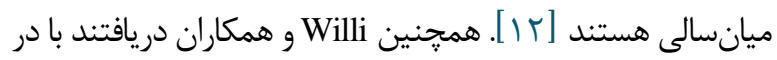

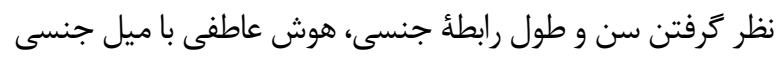
زنان ارتباط معكوسى دارد [ب آ إ]. بامنظور ارتقاى سطح بجزيستى روانشناختى و عملكرد جنسى دانى

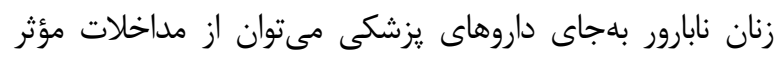

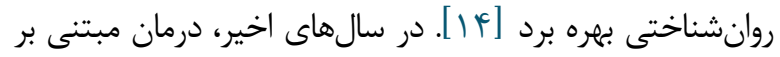

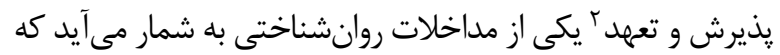

1. Sexual Function

${ }^{2}$. Acceptance and CommitmentTherapy

3 . Defusion

${ }^{4}$. Acceptance

5 . Contact with the present Moment

${ }^{6}$. Observing Self

7. Values 
مجدد، از شركت كنند أن دعوت شد يرسشنامههاى مذكور را

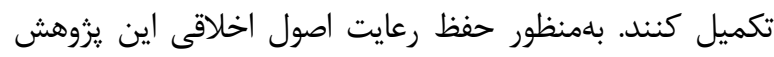

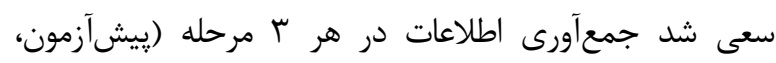

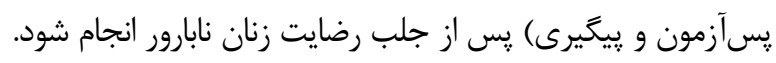

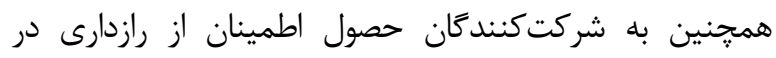

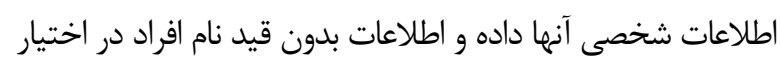
يزوهشكر كذاشته شد.

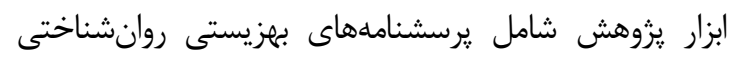

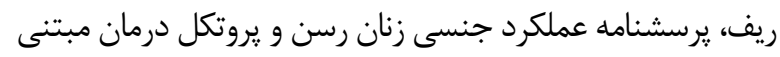
بر يذيرش و تعهد واولز و سورل است:

ير بشنامة بهزيستى روانشناختى Reff (1919) بلمنظور سنجش بهزيستى روانشناختى، از فرم كوتاه

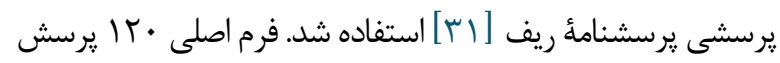

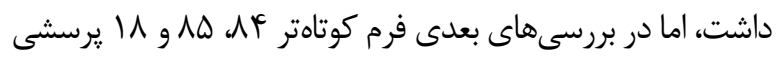

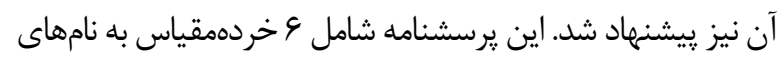

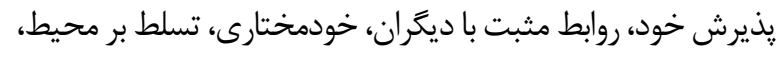

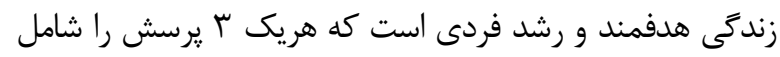

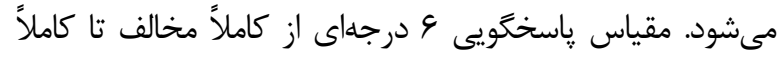

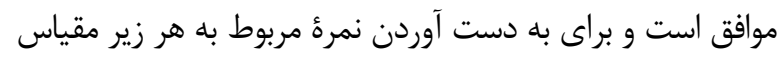

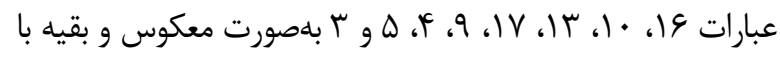

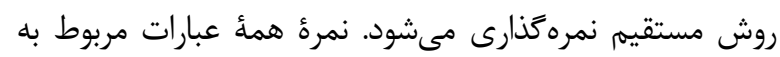

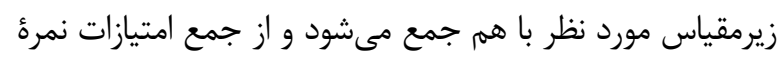

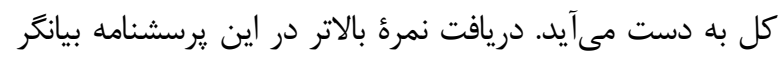

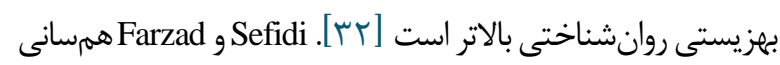

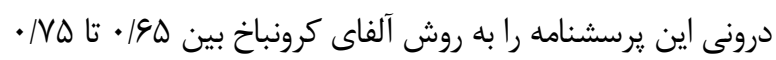

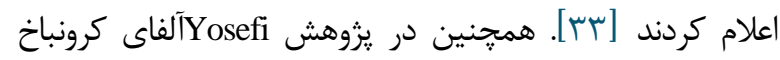

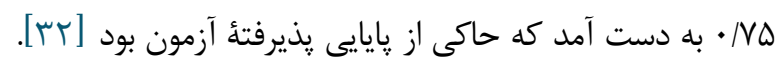

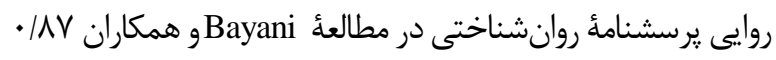

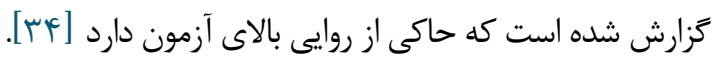

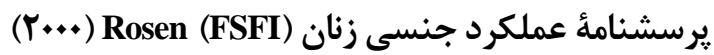

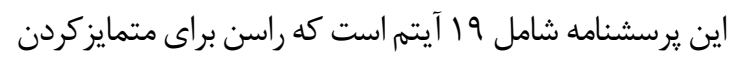

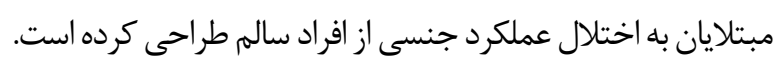

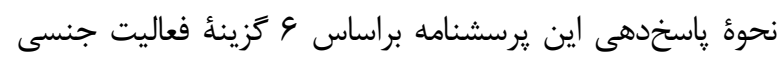

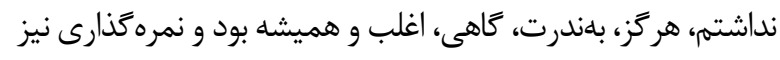

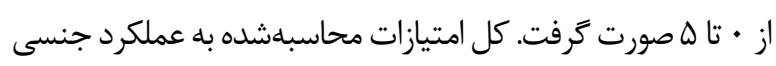

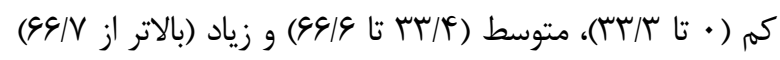

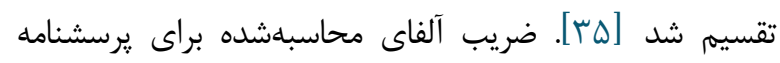

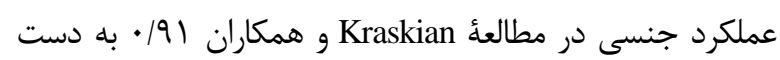

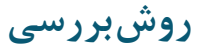

يزوهش حاضر مطالعهاى نيمهتجربى با طرح ريش ريش آزمون-

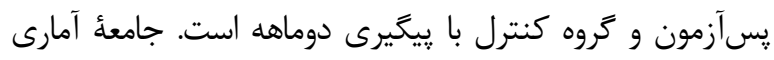

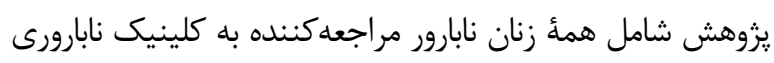

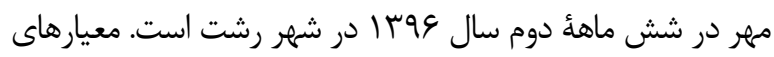

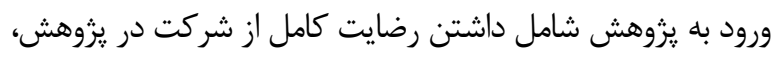

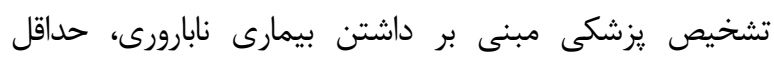

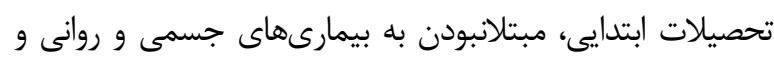

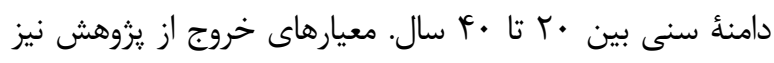

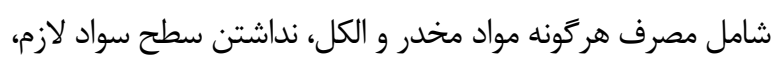

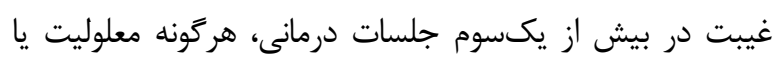

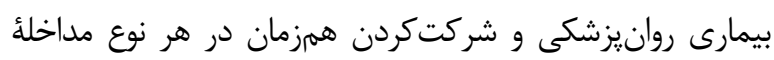
آموزشى ديكر.

بلمنظور تعيين حجم نمونه از مطالعات مشابه [4 ا [ ] استفاده

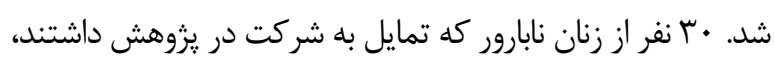

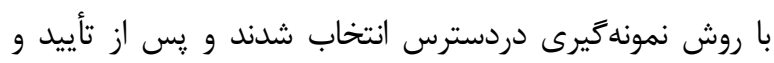

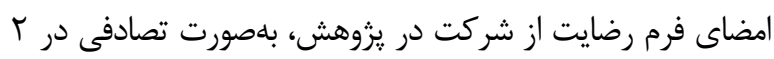

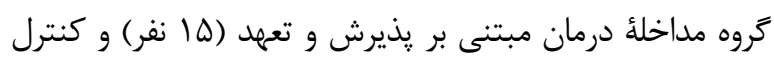

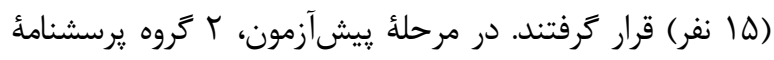

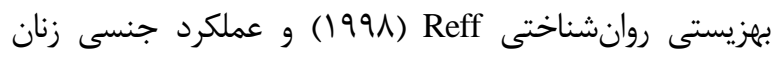
Rosen

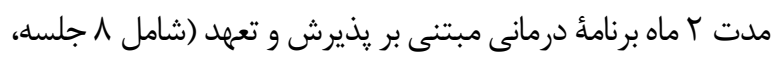

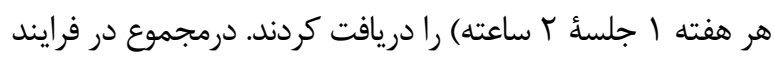

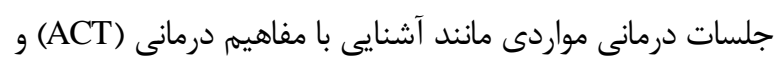

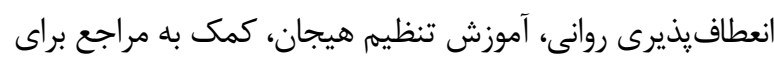

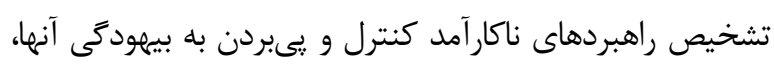

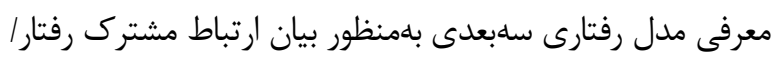

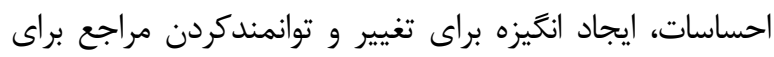
زندى بهتر آموزش داده شد.

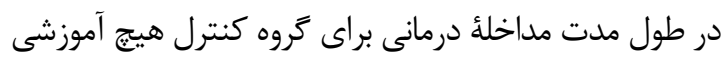

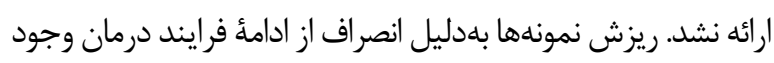

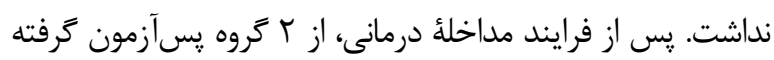

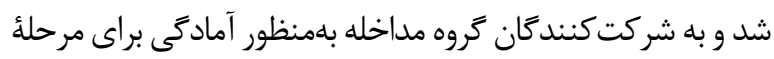

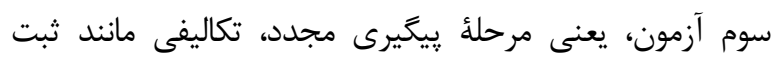

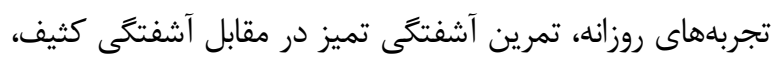

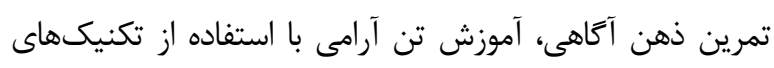

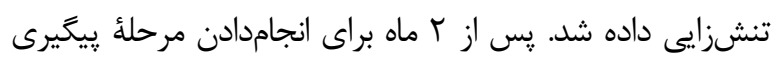


شيوه درمانى استفادهده در اين يزوهش، درمان مبتنى بر يذيرش و تعهد بود. در اين شيوه تلاش مىشود بهجاى تغيير

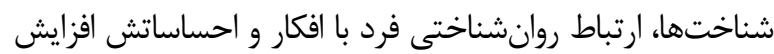

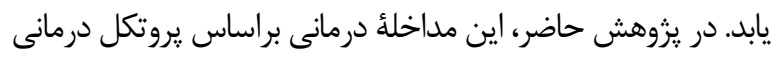

$$
\text { واولز و سورل طرحريزى شد. }
$$

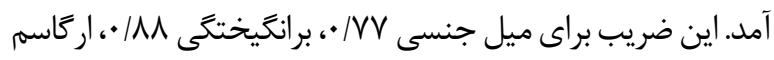

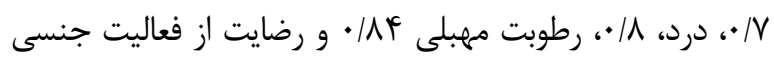

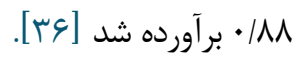

برنامة درمان مبتنى بر يذيرش و تعهد

جدول r. عنوان موضوعات و خلاصهاى از جلسات درمان مبتنى بر يذيرش و تعهد عناوين مطالب ارائهشده

معرفى اعضا، مقدمهاى از انجام كار و پيش آزمون، برقرارى رابطةُ درمانى، مفهومسازى مشكل، آشنايى با مفاهيم درمانى (ACT) و انعطافيذيرى روانى 1

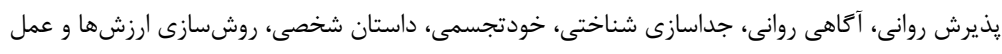

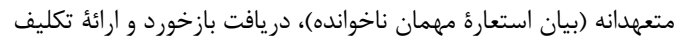

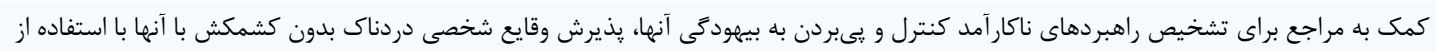

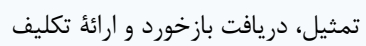

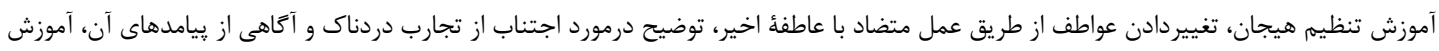

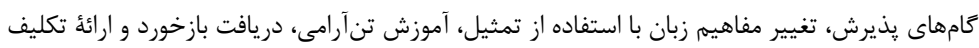

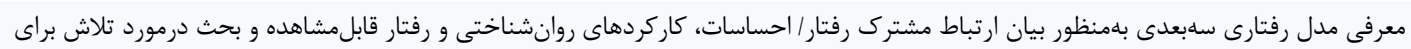

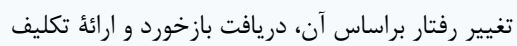

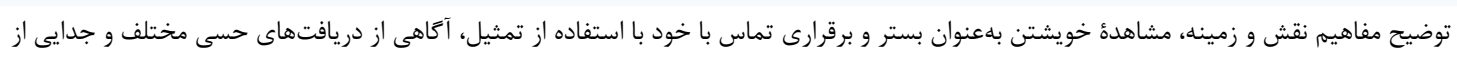

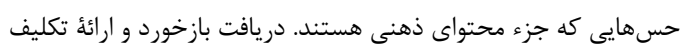

توضيح مفهوم ارزشها، ايجاد انگَيزه براى تغيير و توانمندكردن مراجع براى زندكى بهتر، تمرين تمركزى، دريافت بازخورد و ارائه تكليف r

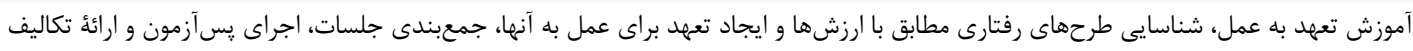

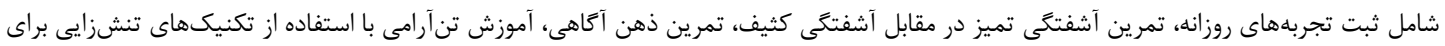

جدول r. اطلاعات جمعيتشناختى شركت كنندگًان

\begin{tabular}{|c|c|c|c|}
\hline درصد & فراوانى & مقوله & \\
\hline$\Delta \cdot 1 \cdot$ & 10 & $r \cdot-r$. & \multirow{2}{*}{ متغير سن } \\
\hline$\Delta \cdot /$ & 10 & MI-r. & \\
\hline 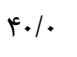 & M & $1-\infty$ & \multirow{2}{*}{ مدتزمان نابارورى } \\
\hline 9.1 & ir & $9-1$. & \\
\hline$r g / V$ & $\wedge$ & زير دييلم & \multirow{4}{*}{ تحصيلات } \\
\hline 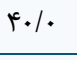 & ir & دييلم و فوقدييلم & \\
\hline س & v & كارشناسى & \\
\hline $1 . \%$ & r & كارشناسى ارشد و دكترا & \\
\hline $99 / \mathrm{V}$ & $r$. & خانهدار & \multirow{2}{*}{ وضعيت شغلى } \\
\hline س/זس & 1. & شاغل & \\
\hline
\end{tabular}

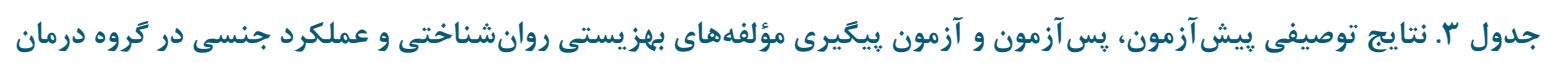
مبتنى بر يذيرش و تعهد و كنترل 


\begin{tabular}{|c|c|c|c|c|c|c|c|c|}
\hline \multicolumn{2}{|c|}{ بيايرى } & \multicolumn{2}{|c|}{ مِ } & \multicolumn{2}{|c|}{ بيشآزمون } & \multirow{2}{*}{ كروه } & \multirow{2}{*}{\multicolumn{2}{|c|}{ متغيرها }} \\
\hline SD & M & SD & M & SD & M & & & \\
\hline $1 / \Delta F$ & $11 / 99$ & $r / A r$ & 18/1 & r/Tळ & $11 / \Delta r$ & آزمايش & \multirow{2}{*}{ يذيرش خود } & \multirow{12}{*}{ روأفهاى بهزيستى } \\
\hline $1 / \cdot 0$ & 1.18 & $r / T \Delta$ & س 1.1 & G/T & سו/ & كنترل & & \\
\hline$r / q T^{c}$ & $q / 4$ & 纤 & $\mid r / \Delta r$ & T/T & $1 . / 14$ & آزمايش & \multirow{2}{*}{ دوابط مثبت بان } & \\
\hline$r / T)$ & $11 / \wedge$. & $1 / 4 \Delta$ & $q / \Delta r$ & $1 / 49$ & س & كنترل & & \\
\hline r/Ar & $1 \pi / r$. & $r / 11$ & $1 f / 4$. & $r / \Psi \wedge$ & $9 / \wedge$. & آزمايش & \multirow{2}{*}{ خودمختارى } & \\
\hline$r / 99$ & $1 \pi / 9$. & $1 / \Delta \Lambda$ & $\mid \omega / \& 9$ & .10. & $1 \pi / 9$. & كنترل & & \\
\hline$r / \mu$ & $1 \pi / 9$. & $r / r r$ & $\| F / \Delta T$ & $r / Q T$ & $11 / 99$ & آزمايش & \multirow{2}{*}{ تسلط بر محيط } & \\
\hline $1 / \Delta \Lambda$ & $9 / 99$ & $r / 11$ & 1./1 & س/ג & $9 / \wedge$. & كنترل & & \\
\hline$r / A r$ & س & $r / \cdot 1$ & $\mid \omega / 4$. & $1 / N r$ & $q / .$. & آزمايش & \multirow{2}{*}{ زندگى هدفمند } & \\
\hline$\Delta / T V$ & $11 / \%$ & $r / 9 \Lambda$ & $1 K / 48$ & $r / \mu r$ & $1 r / \cdot 9$ & كنترل & & \\
\hline$r / \Lambda$. & $\pi / r$. & $r / \Delta q$ & IT/Kg & $r / .9$ & $\mid r / 4$. & آزمايش & \multirow{2}{*}{ رشد فردى } & \\
\hline$r / q$. & IT/N & $r / r r$ & $1 r / r$. & ع ع/r & س & كنترل & & \\
\hline$s / V^{c}$ & $V \Delta / r$. & $1 . / \mathrm{N}^{\mathrm{c}}$ & $\Lambda \Delta / T G$ & $V / r q$ & QD/QT & آزمايش & \multirow{2}{*}{\multicolumn{2}{|c|}{ نمرة كل بهزيستى روانشناختى }} \\
\hline $\mathrm{V} / \cdot \mathrm{f}^{\mathrm{c}}$ & SN/T & $\Lambda / \wedge r$ & $V I / r r$ & N/AT & $W / 99$ & كنترل & & \\
\hline$r / r q$ & $r . / 9$. & $r / v r$ & $r \mu / r$. & $r / \wedge \varepsilon$ & W/T & آزمايش & \multirow{2}{*}{\multicolumn{2}{|c|}{ عملكرد جنسى }} \\
\hline$r / \bullet V$ & $\mathrm{~N} / \cdot 1$ & $T / T \Delta$ & N/99 & $T / V V$ & $\mathrm{IV} / \mathrm{s}$. & كنترل & & \\
\hline
\end{tabular}

جدول F. حليل كواريانس جندمتغيره براى بررسى تأثير درمان مبتنى بر هذيرش و تعهد (ACT) بر مؤلفههاى بهزيستى روانشناختى و عملكرد جنسى در مرحله يس بـ آزمون

\begin{tabular}{|c|c|c|c|c|c|c|c|}
\hline ميزان تأثير & سطح معنى دارى & $\mathbf{F}$ & ميانكَين & درجهُ آزادى & مجموع مجذورات & متغير وابسته & منبع تغييرات \\
\hline 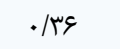 &.$\cdot{ }^{2}$ & IT/GFY & $\Delta \& / \Lambda 19$ & 1 & $\Delta \& / \Lambda 1 q$ & يذيرش خود & كروه - ك اه \\
\hline$\cdot / \mu$ &.$\cdot \cdot v$ & N/VQF & $\Delta N / \cdot \Delta \varphi$ & 1 & $\Delta N / \cdot \Delta S$ & روابط مثبت با ديخران & \\
\hline.$/ 18$ &.$/ \cdot k T$ & r/\&Nr & $r V / I 1 /$ & 1 & $r V / M I N$ & خودمختارى & \\
\hline $.1 \cdot r$ &.$/ F T F$ & 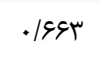 & ( ) & 1 & 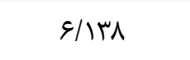 & تسلط بر محيط & \\
\hline$\cdot / 1 \Lambda$ & ( & D/.ra & GI/DF & 1 & G)/DF & زندگى هدفمند & \\
\hline $.1 \cdot r$ & $\cdot 10 \cdot 1$ &.$/ 491$ & $8 / 499$ & 1 & $9 / 599$ & ر ر رددى & \\
\hline$\cdot / 4 \wedge$ &.$\cdots$ & ra/Gre & $r \cdot r \cdot / V T E$ & 1 & $r \cdot r \cdot / V T S$ & نمرة كل بهزيستى روانشناختى & \\
\hline . / F &.$/$. & $r \cdot / r q T$ & $|r \varepsilon| \cdot \wedge \mid$ & 1 & $|r \varepsilon| \cdot \wedge \mid$ & عملكرد جنسى & \\
\hline
\end{tabular}

بافته ها

براساس نتايج تحليل كواريانس קُندمتغيره، درمان ACT اطلاعات جمعيتشناختى شركت كنندكان به تفكيك گروه

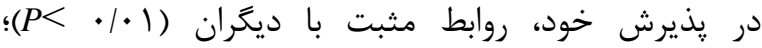
آزمايش (درمان ACT) و گروه كنترل نشان داده شده است. خودمختارى، زندگى هدفمند (ه •|• > > • ب نفر از شركت كنند كان در دو گروه قرار دارند. وضعيت سنى، بهزيستى روانشناختى و عملكرد جنسى ( ( • • > > زمان نابارورى، تحصيلات و وضعيت شغلى شركت كنند مثبتى دارد. همجنين نتايج نشان مىدهد درمان ACT در جدول شماره r ذ ذكر شده است. همجنين نتايج توصيفى مؤلفههاى تسلط بر محيط و رشد فردى تأثير معنى دارى ندارد

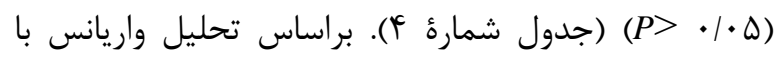

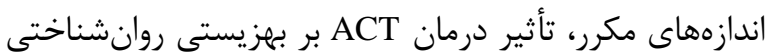
ييشآزمون، يسآزمون و آزمون بيخيرى مؤلفههاى بهزيستى

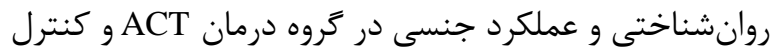
آمده است (جدول شماره بن). 
با ديكران و زندگى هدفمند (ه•|• حفظ شده است (جدول شماره له).
شامل نمرة كل بهزيستى روانشناختى و عملكرد جنسى

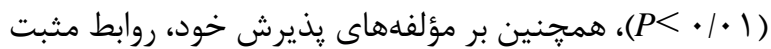

جدول ه. نتايج تحليل واريانس با اندازههاى مكرر براى بررسى تأثير درمان مبتنى بر بذيرش و تعهد (ACT) بر مؤلفههاى بجزيستى

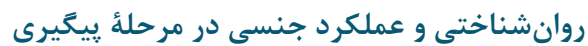

\begin{tabular}{|c|c|c|c|c|c|c|c|}
\hline ميزان تأثير & Sig & $\mathbf{F}$ & ميانكين مجذورات & آزادى & مجموع مجذورات & منبع تغييرات & متئير \\
\hline . &.$/ . r \Delta$ & r/qrI & $\| F / \lambda .$. & r & $r q / q .$. & اثر مرحله & يذيرش خود \\
\hline.$/ 4 F$ &.$/ .11^{c}$ & $r / \Delta \Lambda$. & rN/FE & r & ve/rAq & اثر مرحله & روابط مثبت با ديكران \\
\hline $.1 . r$ & $\cdot|F V|$ & - /vGr & $v / \Delta \cdot$. & r & $\mid \Delta / . .1$ & اثر مرحله & خودمختارى \\
\hline .1 .9 & .1 .91 & r/qTه & $r \cdot / \Lambda \cdot$. & r & $f \mid / q .$. & اثر مرحله & تسلط بر محيط \\
\hline . $/ 1 r$ & (1.4 & $r / q \cdot \Delta$ & $s \% / v .$. & r & $\mid T / / F$. & اثر مرحله & ز زلدگى هدفمند \\
\hline .1 .0 & $\cdot / \pi r r$ & I/FV & $1 F / A v$. & r & $r q / V \Delta S$ & اثر مرحله & ر رشد فردى \\
\hline$\cdot r$. & /..r & $v / r q \Delta$ & 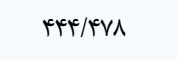 & r & $M M / q \Delta S$ & اثر مرحله & نمرة كل بهزيستى روانشناختى \\
\hline و &.$/ .1$ & ।ه/q४q & S9/Tr & r & ITY/FVG & اثر مرحله & عملكرد جنسى \\
\hline
\end{tabular}

بحث

و همكاران [عץ] كه نشان دادند درمان ACT بر بيماران مبتلا

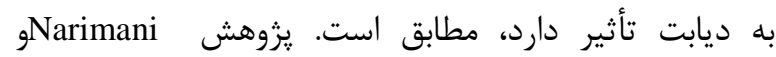

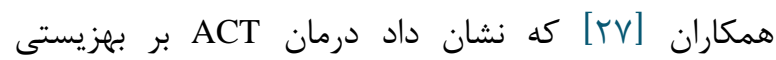

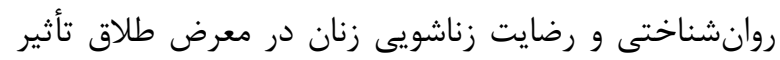

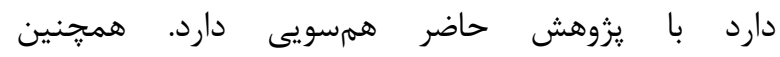

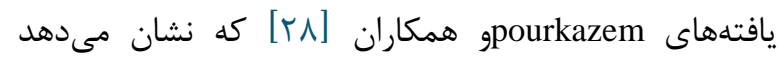
درمان ACT بر بهزيستى روانشناختى افراد مبتلا به تراجنسى دمانى

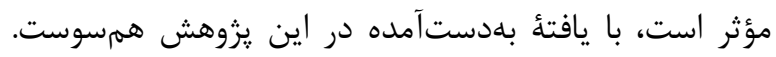

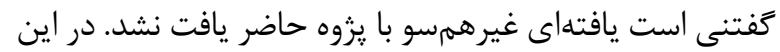
راستا، Saadatmand و همكاران دريافتند كه اثربخش برونى

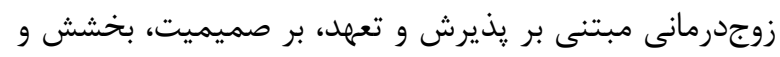

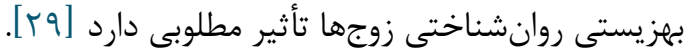

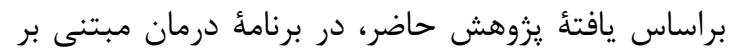

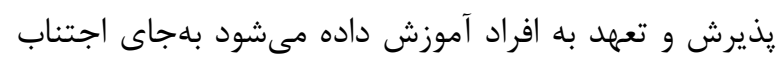
فكرى و عملى، از افكار و موقعيتهاى اجتماعى استفاده كنند. همجنين با افزايش يذيرش روانى وضعيت زندكى خود را بهبود إنى بخشند، به ارزشهاى شخصى برسند و مشكلات اجتنابنانيذير

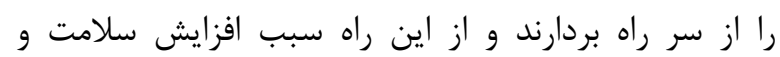

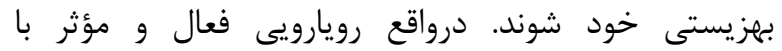

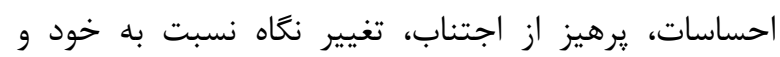

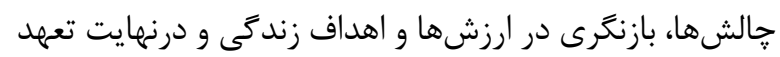
به هدف را مىتوان جزء عوامل اصلى اين روش دانست كه اين
نابارورى يكى از مشكلات عمده جوامع امروزى است كه ييامدهاى روانى و عاطفى زيادى را متوجه زوجين مى كند.

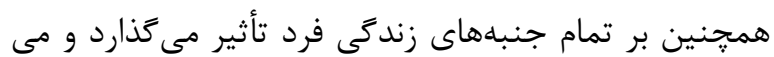

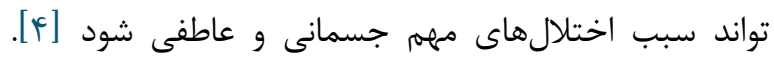
برخى مطالعات نشان مىدهد زنانى كه تجربأ نابارورى دارند

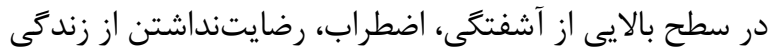

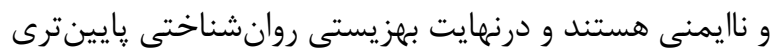

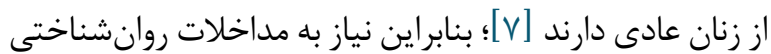
براى اين كروه از زنان ضرورى به نظر مىرسد.

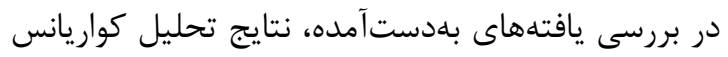

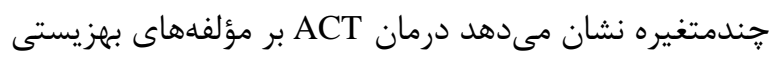
روانشناختى شامل يذيرش خود، روابط مثبت با ديكران،

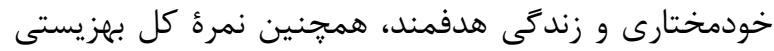

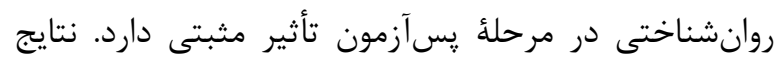
تحليل واريانس با اندازههاى مكرر نيز نشان ميى دهد كه درمان ACT بر مؤلفههاى بهزيستى روانشناختى شامل يذيرش خود،

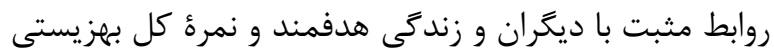

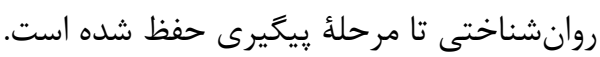

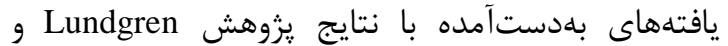

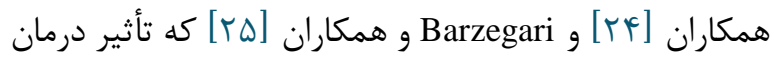
بCT بهزيستى روانشناختى بيماران مبتلا به صرع را بيان

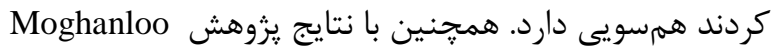


محدوديتهاى يزوهش حاضر شامل استفاده از روش نمونهگيرى در دسترس در مرحلة اول نمونه

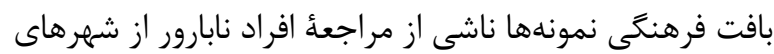

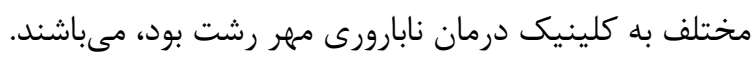

\section{نتيجه گَيرى}

نتايج يزوهش حاضر نشان ميدهد كه درمان ACT سبب ارتقاى سطح بهزيستى روانشناختى و عملكرد جنسى زنان نابارور مىشود. اين نتيجه مىتواند نقطهُ عطفى در درمان

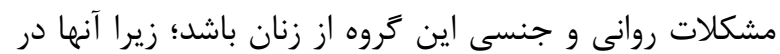

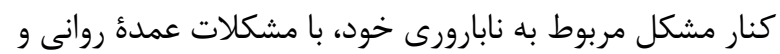
هيجانى نيز مواجه هستند كه بلنوعى زندكى آنها را دورجندان

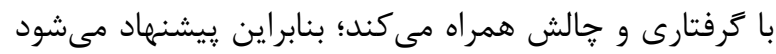

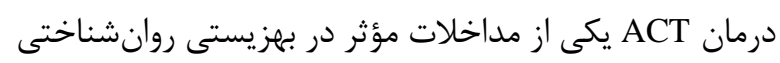

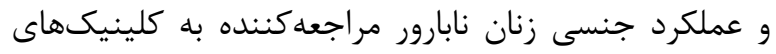

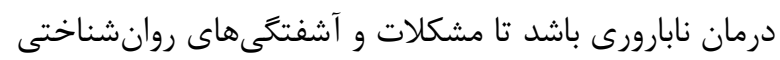
و جنسى آنها كاهش يابد.

\section{سياسگزارى}

از خانم دكتر مهرافزا مديريت كلينيك درمان ناباورى مهر

در شهر رشت، همأ شركت كنند

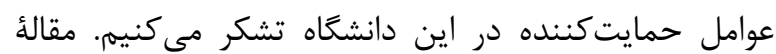

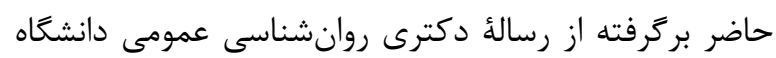

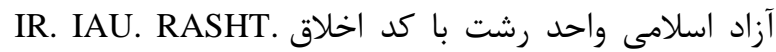

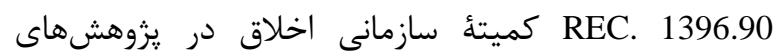

$$
\text { زيست بزشكى است. }
$$

\section{تعارض در منافع}

بين نويسندكان هيجزَنه تعارضى در منافع وجود ندارد

\section{منابع مالى}

اين مقاله بخشى از رساله دكترى و حامى مالى آن دانشعاه

$$
\text { تربيتمدرس بود. }
$$

عوامل به كمك بهبود مهارتهاى اجتماعى و روابط اجتماعى سبب افزايش انعطافيذيرى شناختى و درنهايت منجر به ارتقاى بهزيستى روانشناختى مىشود [rV].

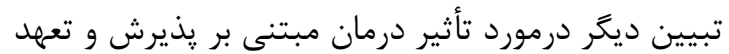
بر بهزيستى روانشناختى زنان نابارور اين است كه اين برنامئ

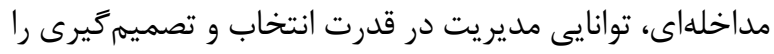
در آنها ارتقا مى دهد. اين امر سبب افزايش تابآورى و تعهد به افراد در شناسايى تنشهاى زندگى، كاهش برانخيختخى هاى روانى و هيجانى، مقابلة سازگار با منابع استرسزا و درنهايت

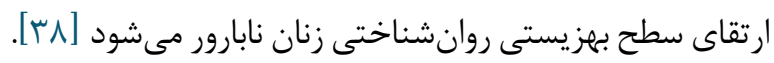

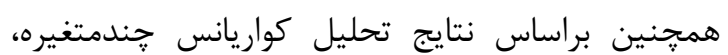
درمان مبتنى بر يذيرش و تعهد (ACT) بر عملكرد جنسى برى زنان نابارور در مرحلة يسآزمون تأثير مثبتى دارد. نتايج تحليل يديل

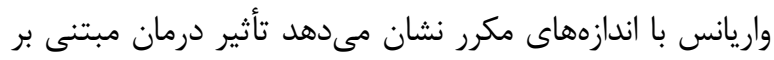

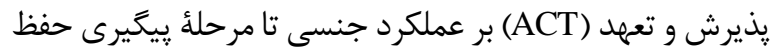

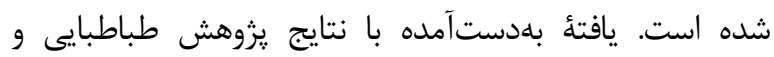

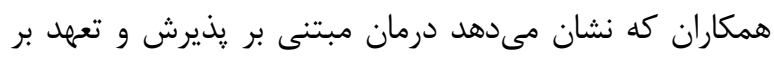
عملكرد جنسى، كمرويى جنسى و جرئتورزى جنسى زنان مبتلا به اختلالات جنسى تأثير مثبتى دارد، همسويى دارد [ـ [ب].

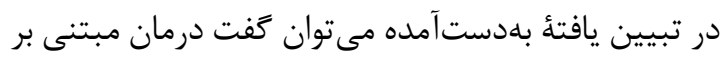

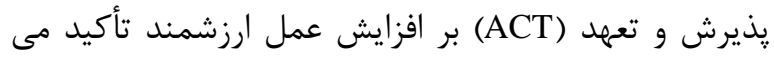
كند؛ بنابراين شركت كنند

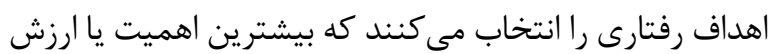
را براى آنان دارد [هץ]. در اين درمانها، ارزش بيش بيش از اينكه نوعى قضاوت اخلاقى باشد، اهميت شخصى عمل خاصى را

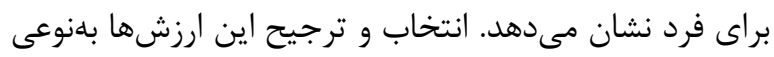
به بهبودى روابط بين فردى، مراقبت از خود و روابط زناشويى باشد كه از اين طريق عملكرد جنسى را ارتقا مى دهد. همجنين اين شيوه درمانى سبب مىشود تا احساس ارزشمندى زندگى

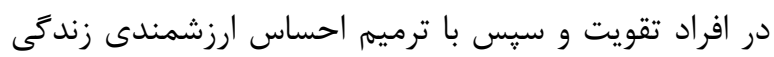
در زنان، زمينه براى افزايش سطح رضايت و عملكرد جنسى لري

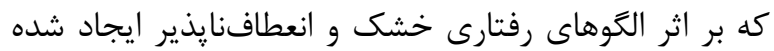
است، فراهم شود [عب].

\section{References}

1. Sadat Hoseini SA. Infertility from the view Point of Forensic Medicine. Iran J Med Law. 2009; 3 (8): 93107. (Persian). 
2. Gautam M, Risal P. Infertility: An Emerging Public Health Issue in Nepal. Annals of Clinical Chemistry and Laboratory Medicine. 2017;3(1):1-2. [DOI:10.3126/acclm.v3i1.17717]

3. Direkvand Moghadam A, Delpisheh A, Sayehmiri K. The prevalence of infertility in Iran, a systematic review. The Iranian Journal of Obstetrics, Gynecology and Infertility. 2013;16(81):1-7.

4. Smeenk JM, Verhaak CM, Eugster A, Van Minnen A, Zielhuis GA, Braat DD. The effect of anxiety and depression on the outcome of in-vitro fertilization. Human Reproduction. 2001 Jul 1;16(7):1420-3. [DOI:10.1093/humrep/16.7.1420] [PMID]

5. Van den Broeck U, Emery M, Wischmann T, Thorn P. Counselling in infertility: individual, couple and group interventions. Patient education and counseling. 2010 Dec 1;81(3):422-8. [DOI:10.1016/j.pec.2010.10.009] [PMID]

6. Diener E, Oishi S, Lucas RE. Personality, culture, and subjective well-being: Emotional and cognitive evaluations of life. Annual review of psychology. 2003 Feb;54(1):403-25.

[DOI:10.1146/annurev.psych.54.101601.145056] [PMID]

7. Miles LM, Keitel M, Jackson M, Harris A, Licciardi F. Predictors of distress in women being treated for infertility. Journal of Reproductive and Infant Psychology. $2009 \quad$ Aug 1;27(3):238-57. [DOI:10.1080/02646830802350880]

8. Safarinia M, Aghayousefi AR, Baradaran M. The relationship between personality aspects, problem solving and psychological well-being the role of narcissism. Counsel Psychother Culture2014. 2014;5:89-102.

9. Alizadeh A, Soleimani F, Barati H, Azizi M. The assessment of sexual function in female nurses and housewives. Military Caring Sciences Journal. 2015 Sep $15 ; 2(2): 115-9$ [DOI:10.18869/acadpub.mcs.2.2.115]

10. Bayrami R, Sattarzadeh N, Koochaksariie FR, Pezeshki MZ. Sexual dysfunction in couples and its related factors during pregnancy. Journal of Reproduction \& Infertility. 2008 Oct 1;9(3).

11. Abdolmanafi A, Owens RG, Winter S, Jahromi RG, Peixoto MM, Nobre P. Determinants of women's sexual dissatisfaction: Assessing a cognitiveemotional model. The journal of sexual medicine. 2016 Nov 1;13(11):1708-17. [DOI:10.1016/j.jsxm.2016.08.013] [PMID]

12. Thomas HN, Thurston RC. A biopsychosocial approach to women's sexual function and dysfunction at midlife: A narrative review. Maturitas. 2016 May 1;87:49-60. [DOI:10.1016/j.maturitas.2016.02.009] [PMID] [PMCID]

13. Willi J, Burri A. Emotional Intelligence and Sexual Functioning in a Sample of S wiss Men and Women. The journal of sexual medicine. 2015 Oct;12(10):2051-60. [DOI:10.1111/jsm.12990] [PMID]
14. Bavadi B, Poursharifi H, Lotfi Kashani F. The Effectiveness of Cognitive-Behavioral Therapy Based 8-step Pattern of Cash to Improve Psychological wellbeing of Women with Breast Cancer. Irani Quar J of Brea Dise. 2016; 8(4): 41-51.

15. Roditi D, Robinson ME. The role of psychological interventions in the management of patients with chronic pain. Psychol Res Behav Manag. 2011; 4(1): 41-9. [DOI:10.2147/PRBM.S15375] [PMID] [PMCID]

16. Hayes SC, Luoma JB, Bond FW, Masuda A, Lillis J. Acceptance and commitment therapy: Model, processes and outcomes. Behaviour research and therapy. 2006 Jan 1;44(1):1-25. [DOI:10.1016/j.brat.2005.06.006] [PMID]

17. Hayes SC, Pistorello J, Levin ME. Acceptance and commitment therapy as a unified model of behavior change. The Counseling Psychologist. 2012 Oct;40(7):976-1002. [DOI:10.1177/0011000012460836]

18. Zettle RD, Rains JC, Hayes SC. Processes of change in acceptance and commitment therapy and cognitive therapy for depression: A mediation reanalysis of Zettle and Rains. Behavior modification. 2011 May;35(3):265-83. [DOI:10.1177/0145445511398344] [PMID]

19. Twohig MP, Hayes SC, Masuda A. Increasing willingness to experience obsessions: Acceptance and commitment therapy as a treatment for obsessivecompulsive disorder. Behavior therapy. 2006 Mar 1;37(1):3-13. [DOI:10.1016/j.beth.2005.02.001] [PMID]

20. Twohig MP. Acceptance and commitment therapy for treatment-resistant posttraumatic stress disorder: A case study. Cognitive and Behavioral Practice. 2009 Aug

$1 ; 16(3): 243-52$ [DOI:10.1016/j.cbpra.2008.10.002]

21. López FJ. Acceptance and Commitment Therapy (ACT) in the treatment of panic disorder: Some considerations from the research on basic processes. International Journal of Psychology and Psychological Therapy. 2009;9(3):299-316.

22. Roemer L, Orsillo SM. An open trial of an acceptancebased behavior therapy for generalized anxiety disorder. Behavior therapy. 2007 Mar 1;38(1):72-85. [DOI:10.1016/j.beth.2006.04.004] [PMID]

23. Twohig MP, Hayes SC, Masuda A. A preliminary investigation of acceptance and commitment therapy as a treatment for chronic skin picking. Behaviour Research and Therapy. 2006 Oct 1;44(10):1513-22. [DOI:10.1016/j.brat.2005.10.002] [PMID]

24. Lundgren T, Dahl J, Melin L, Kies B. Evaluation of acceptance and commitment therapy for drug refractory epilepsy: a randomized controlled trial in South Africa-a pilot study. Epilepsia. 2006 Dec;47(12):2173-9. [DOI:10.1111/j.15281167.2006.00892.x] [PMID]

25. Barzegaridehaj A. efficiency of the acceptance and commitment therapy on individuals psychological

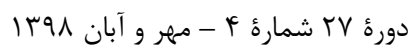

$$
\text { مجله مراقبت يرستارى و مامايى ابنسينا }
$$


well-being in people with epilepsy in Imam Hossein Hospital in the autumn and winter of 2015 . scientific journal of ilam university of medical sciences. 2017;25(1):138-47. [DOI:10.29252/sjimu.25.1.138]

26. Moghanloo VA, Moghanloo RA, Moazezi M. Effectiveness of acceptance and commitment therapy for depression, psychological well-being and feeling of guilt in 7-15 years old diabetic children. Iranian journal of pediatrics. 2015 Aug;25(4). [DOI:10.5812/ijp.2436] [PMID] [PMCID]

27. Narimani M, Bakhshyesh R. [The effectiveness of acceptance commitment training on the psychological well-being, emotional and marital satisfaction in divorce]. Counsel J 2015;13:108-23. (Persian).

28. pourkazem F, Eshghi Nogourani R. The Effectiveness of Treatment Based on Acceptance and Commitment to Improving Psychological Well-Being of Transsexual Individuals Esfahan. Shenakht Journal of Psychology and Psychiatry. 2018; 5 (1):29-41. (Persian). [DOI:10.29252/shenakht.5.1.29]

29. Saadatmand, Kh., Basaknejad, S. Acceptance and Commitment therapy of intimacy, for giveness and psychological Well-bing of couples, Masters, Shahid Chamran University. (Persian).

30. Tabatabayi AS, Sajjadian I, Motamedi M. Effectiveness of Acceptance and Commitment Therapy on Sexual Function, Sexual SelfConsciousness and Sexual Assertiveness among Women with Sexual Dysfunction. J Res Behav Sci 2017; 15(1): 84-92. (Persian).

31. Ryff CD. Happiness is everything, or is it? Explorations on the meaning of psychological wellbeing. Journal of personality and social psychology. 1989 Dec;57(6):1069. [DOI:10.1037/0022$\underline{3514.57 .6 .1069]}$

32. Yosefi M. Comparison of Happiness, Psycholigy Well-Being and Job Perfectionism among Women Nurses of Different Sections of Haspitals in Isfahan at 2014. Sci J Hamadan Nurs Midwifery Fac. 2015; 23 (2): 52-62. (Persian)

33. Sefidi FA, Farzad V. Validated measure of Ryff psychological well-being among students of Qazvin University of Medical Sciences (2009). Journal of Qazvin University of Medical Sciences. 2012 Jan 1;16(1):66-71.

34. Bayani AA, Mohammad Koochekya A, Bayani A. Reliability and validity of Ryff's psychological wellbeing scales. Iranian journal of psychiatry and clinical psychology. 2008 Aug 15;14(2):146-51.

35. Tahmasebi H, Abasi E. Sexual Function and its Relation with Depression in Referring Women to Health Centers Affiliated to Medical Science University in Sari Township. Quar J of Heal Bre. 2013; 1(3): 40-44. (Persian).

36. Kraskian Mujembari A, Keybollahi T. Compile and Standardization of Tehran Married Women Sexual Function Questionnaire (Tehran-SFQ). Mod Care J. 2014; 11 (1): 44-54. (Persian).
37. Moradzadeh F, Pirkhaefi A. The Effectiveness of Acceptance and Commitment Therapy on Marital Satisfaction and Cognitive Flexibility among Married Employees of the Welfare Office. IJPN. 2018; 5 (6): 17. (Persian). [DOI:10.21859/ijpn-05061]

38. Amanollahi A, Zare M, Rajabi GH. The effectiveness of acceptance and commitment therapy on acceptance and growth after break up in female students with break-up experience. $j$ of coun rese. 2018; 15 (64):429. (Persian).

39. Mojdeh F, Mohamadi SZ. The relationship between depression and sexual function index among married women. Scientific Journal of Hamadan Nursing \& Midwifery Faculty. 2013 May 15;21(1):41-51. 